\title{
Immunological Reason for Mild Effection of Children to COVID-19, A Key Factor for Novel Solution of Vaccination and Medications
}

\author{
Esmaeil Farshi ${ }^{1}$ and John Smith $^{2}$ \\ ${ }^{1}$ Peace and Health Organization \\ ${ }^{2}$ Peace and Health Org
}

October 9, 2020

\begin{abstract}
Coronaviruses are important human and animal pathogens. We will show that probably antibodies don't have essential role in immunity against COVID-19 in long term, but a type of white globules named T cells may have critical role in immunity against COVID-19. T cells have long time memory to remain in blood. The most important point for investigation of such issue is mild effection of children to COVID-19. While the milder COVID-19 disease in children is remained secretly till this paper, but its understanding will provide important information about the disease. It may also suggest important protective mechanisms and targets for future therapies. Then a main factor in producing a vaccine for COVID-19 maybe consideration of mild infection report of children by COVID-19 comparing adults' infection that causes conclusion of higher resistance of immune system of children comparing adults. We identified this could be because immunity of children is based on innate immunity (phagocytes) while adults are based on antibodies. Our results show innate immune system including phagocytes contribute severely to the elimination of COVID-19 in both mouse model and human. Our results also show the elimination of COVID-19 required the activation of B cells by CD4+ T cells. CD4+ T cells play an important role in elimination of COVID-19 in primary effection. We measured IgM and IgG in human patients including adults and kids and found that IgM and IgG in kids' patients are much higher than other adults patients.
\end{abstract}

\section{Hosted file}

Effection Childrdn Ep.pdf available at https://authorea.com/users/365853/articles/485793immunological-reason-for-mild-effection-of-children-to-covid-19-a-key-factor-for-novelsolution-of-vaccination-and-medications 


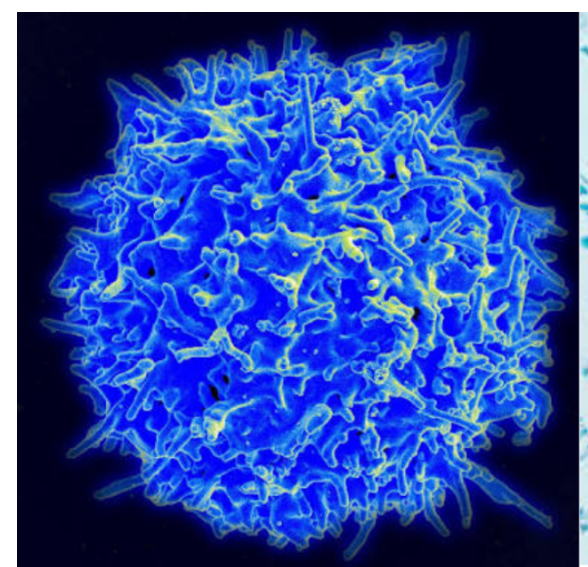

a) $T$ cell

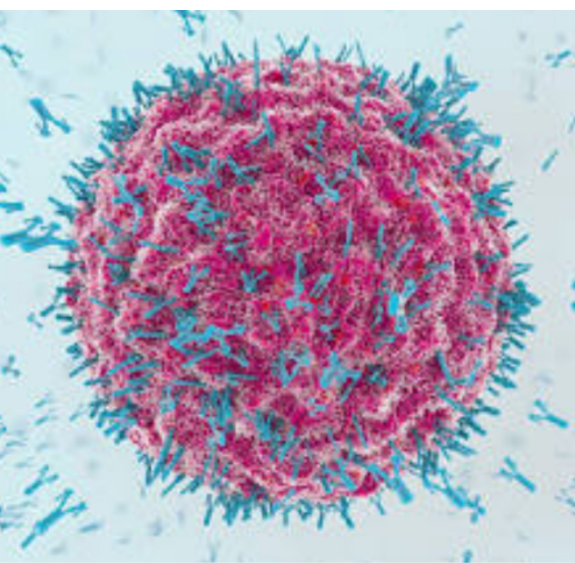

b) $\mathrm{B}$ cell

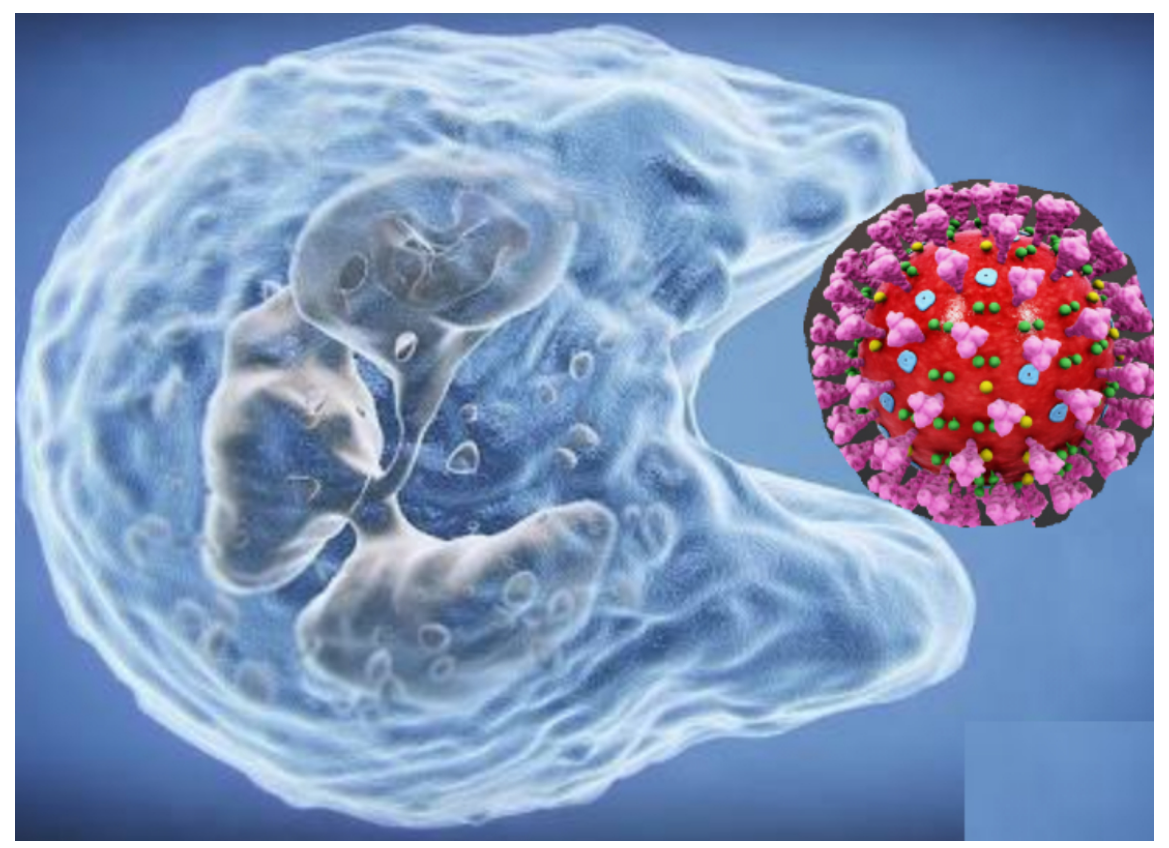



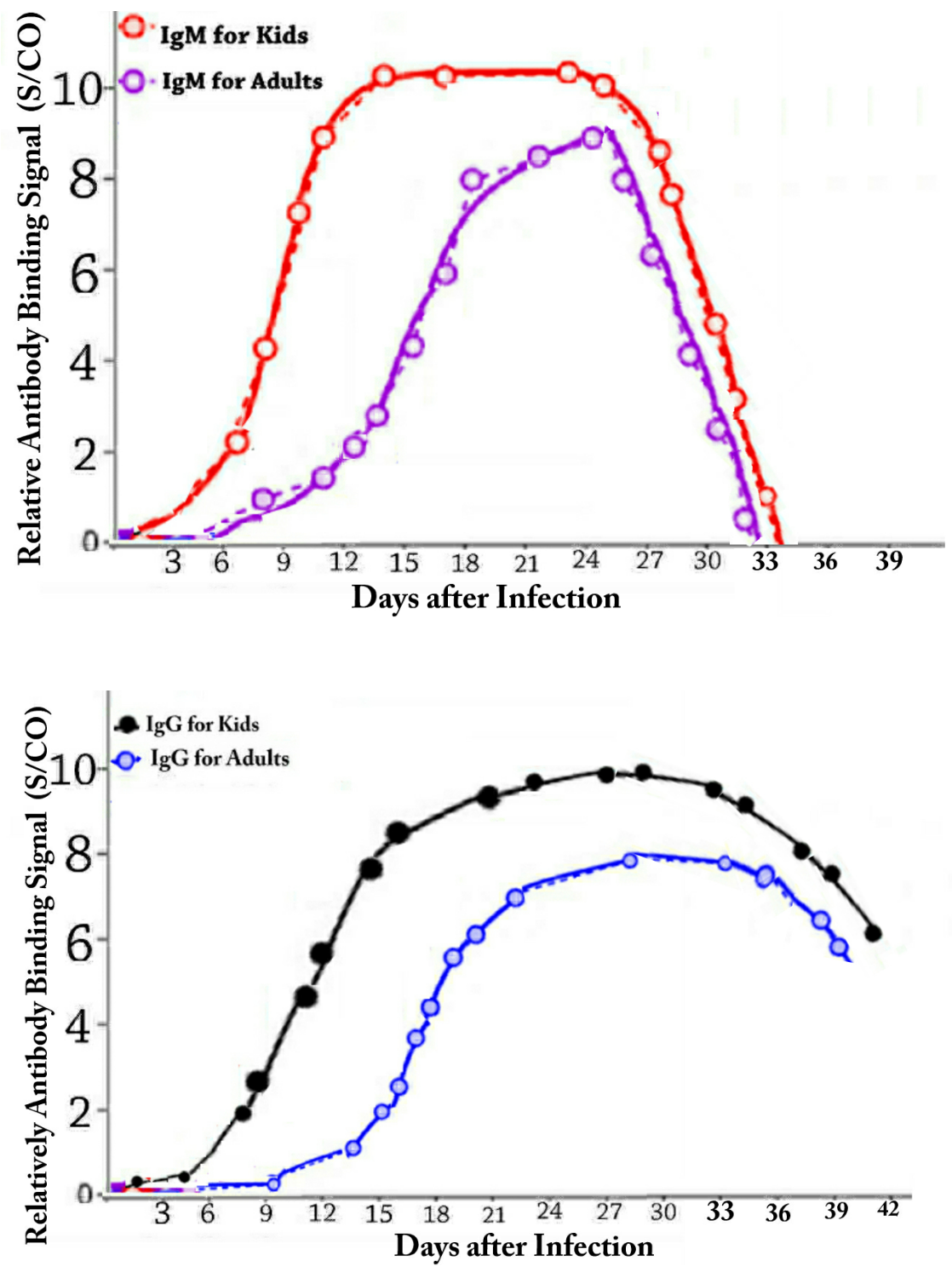


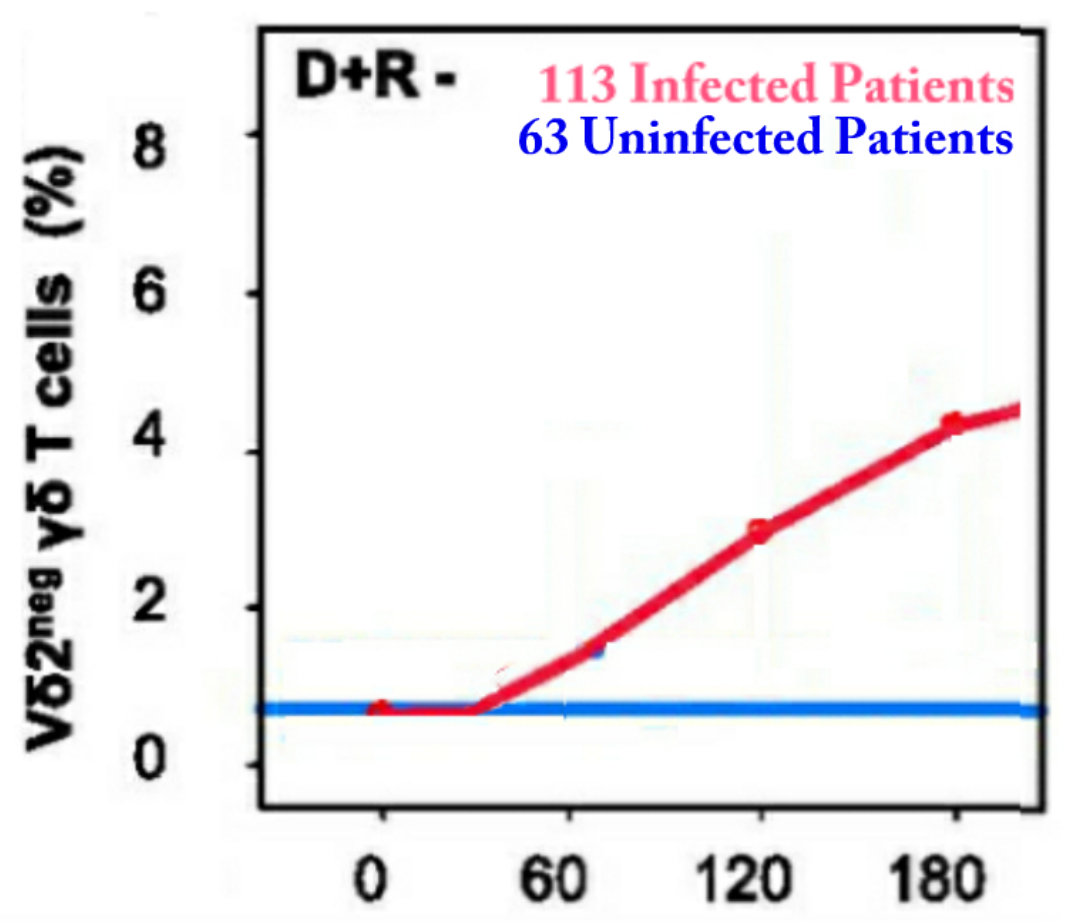

Days after COVID-19 Infection
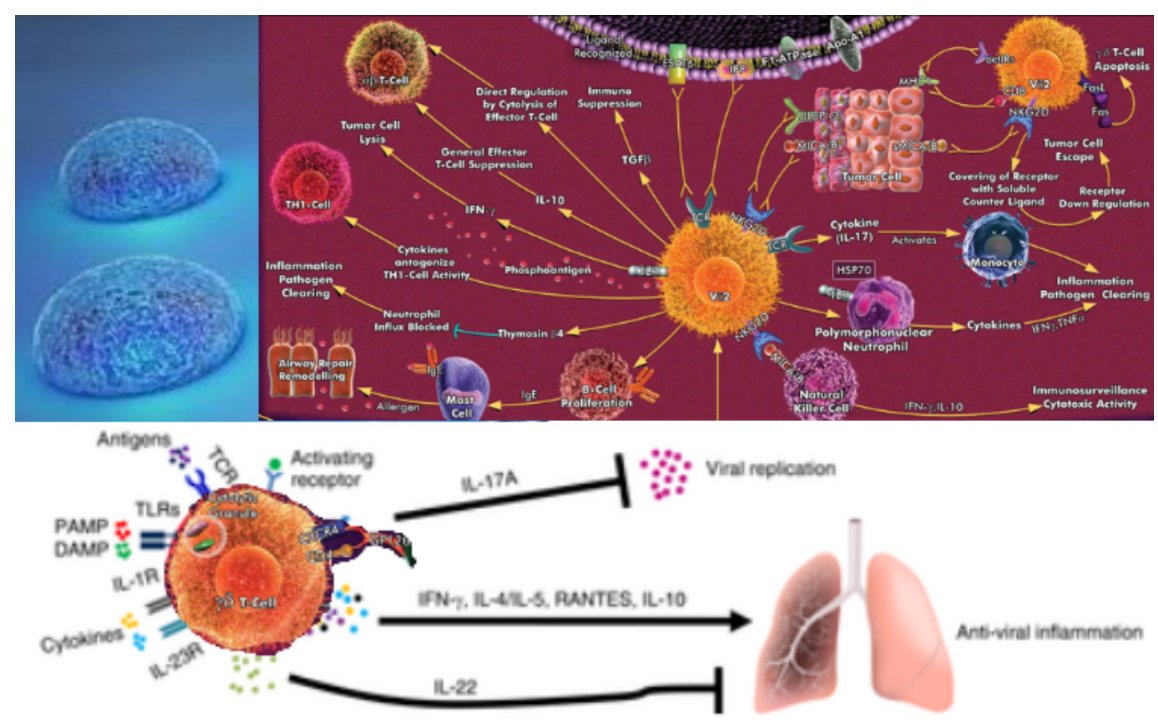

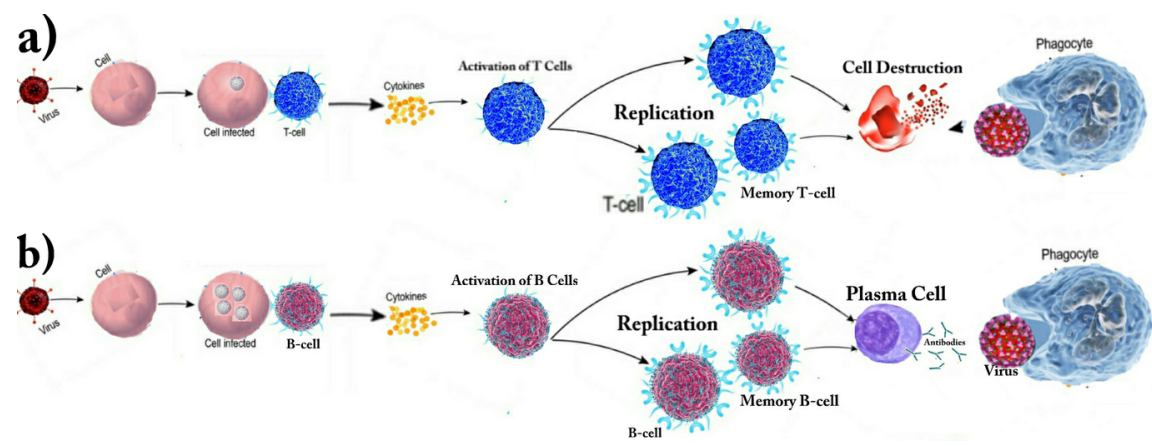